\title{
Construction Technology and Mechanical Properties of a Cement-Soil Mixing Pile Reinforced by Basalt Fibre
}

\author{
Yingwei Hong, ${ }^{1,2}$ Xiaoping $W u,{ }^{1,3}$ and Peng Zhang ${ }^{4}$ \\ ${ }^{1}$ Key Laboratory of Engineering Structure of Heavy Railway, Ministry of Education, Central South University, Changsha, \\ Hunan 410004, China \\ ${ }^{2}$ Communications Design Institute Co., Ltd. of Jiangxi Province, Nanchang 330002, China \\ ${ }^{3}$ Centre for Transport Studies, University of London, London WC1E 6BT, UK \\ ${ }^{4}$ College of Transportation Science \& Engineering, Nanjing Tech University, Nanjing, Jiangsu 210009, China
}

Correspondence should be addressed to Xiaoping Wu; xpwu@csu.edu.cn

Received 2 September 2016; Accepted 12 February 2017; Published 6 April 2017

Academic Editor: Belal F. Yousif

Copyright (C) 2017 Yingwei Hong et al. This is an open access article distributed under the Creative Commons Attribution License, which permits unrestricted use, distribution, and reproduction in any medium, provided the original work is properly cited.

A new type of cement-soil mixing pile reinforced by basalt fibre is proposed for increasing the bearing capacity of cement-soil mixing piles. This work primarily consists of three parts. First, the process of construction technology is proposed, which could allow uniform mixing of the basalt fibre in cement-soil. Second, the optimal proportions of the compound mixtures and the mechanical properties of the pile material are obtained from unconfined compression strength test, tensile splitting strength test, and triaxial shear test under different conditions. Third, the reliability of the construction technology, optimal proportions, and mechanical properties are verified by testing the mechanical properties of the drilling core sample on site.

\section{Introduction}

Cement-soil mixing piles are widely used for reinforcement and waterproofing curtains in soft soil sites due to the flexible reinforcement form, decreased construction disturbance, and low cost. In foundation pit engineering, the lower horizontal bearing capacity of the pile is lower relative to the vertical bearing capacity, so cement-soil mixing piles are only used for waterproof curtains. The enhancing of horizontal bearing capacity and lateral rigidity would enhance the nondeformability of the soil behind the piles, decrease the deformation that causes upheaval and settlement, and reduce the project cost by decreasing the thickness of the gravity retaining wall and the amount of rigid retaining piles.

Several methods have been studied in regard to the defection of cement-soil mixing piles by adding one or more materials, primarily including soil condensates, mineral admixtures, and additives [1]. For the soil condensates, Osula [2] found that lime mixed in cement-soil had a larger impact on increasing its strength compared to cement alone. Wentai [3] increased the durability of cement-soil by $18 \%$ by mixing coal ash and a strong base and so forth. It was shown that the strength of the mixtures slightly increased with the increase in coal ash. Nanometre-scale silicon mixed in the cement-soil could promote hydration reactions with $\mathrm{CaOH}$ in the cement and enhance its strength in each age, especially the early age [4]. For the mineral admixture, polypropylene fibres and fibreglass have been used to improve the performance of cement-soil [5]. The peak strength and residual strength all increase, and the brittleness gradually decreases with the increases in fibreglass [6]. For additives, Tong [7] mixed $\mathrm{Al}(\mathrm{OH})_{3}$ in cement-soil to enhance its strength and analysed the curing mechanism. Huang et al. [8] mixed gypsum in cement-soil at $5 \%$ of the cement mass and found that gypsum has a positive impact on the early strength of cement-soil and can enhance the unconfined compressive strength in a short time. Wu [9] conducted unconfined compressive tests on the cement-soil samples mixed with gypsum, tris(2-hydroxyethyl)amine, and $\mathrm{CaCl} 2$ and found that tris(2-hydroxyethyl)amine can significantly enhance the early strength and, to a lesser extent, the later strength.

Basalt fibre is a filament drawn from cooled basalt ore that has been melted in a furnace at a temperature of $1450^{\circ} \mathrm{C} \sim$ $1500^{\circ} \mathrm{C}$. Basalt fibre has the same composition as basalt ore 


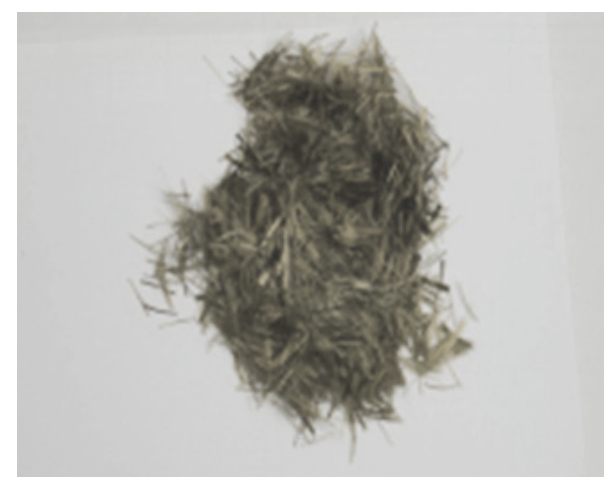

FIgure 1: Basalt fibre.

and can directly break down to be soils [10]. Compared to other additives, basalt fibres have not only environment protecting properties but also a large elasticity modulus, high tensile strength, good corrosion resistance, and stable chemical properties, and so forth [11, 12]. Basalt fibre, as a new reinforcement material, has been widely used in soft and swelling soil to enhance the shear strength, unconfined compressive strength, and swell-shrink capacity [13-15].

A new type of cement-soil mixing pile reinforced by basalt fibre is proposed to enhance the tensile and shear strength and further enhance its lateral rigidity and horizontal bearing capacity. The new pile could be used not only in waterproofing curtain but also in horizontal load-bearing to resist deformation. The following three areas were examined in detail: the optimal ratio of materials to form the cement-soil mixing pile, the method to uniformly mix the basalt fibre in the cement-soil mixing pile, and the engineering effect of cement-soil mixing piles reinforced by basalt fibre.

\section{Mixing Ratio of Materials}

Cement-soil reinforced by basalt fibre can have an enhanced strength by increasing the contact frictional bond stress between the cement-soil and the basalt fibre. However, insufficient basalt fibre mixed in the cement-soil will have a limited impact on the strength and a cement-soil with excess basalt fibre will not cause significant contact friction for strength enhancing. Therefore, the mixing ratio is a crucial parameter. In this study, an unconfined compressive strength test, a tensile splitting strength test, and a triaxial shear strength test, which are closely related to the horizontal bearing capacity of the mixing pile, were conducted on prepared samples to determine the optimal mixing ratio and optimal fibre length.

2.1. Sample Preparation. Three types of materials, namely, soft soil, cement, and basalt fibre, were prepared to manufacture the samples. Soft soil is an underconsolidated, mucky, silty clay from a beach of Yangzi river in the Jiangyin region, Jiangsu province, China. It has a grey colour, liquid-plastic state, slight lustre, medium shake vibration reaction, low tenacity strength and dry strength, and a medium-high compressibility. The cement used was selected composite Portland (P.C32.5). The basalt fibre was a high-strength basalt fibre (see Figure 1) produced by Jiaxing Anlide Construction Co., LTD,

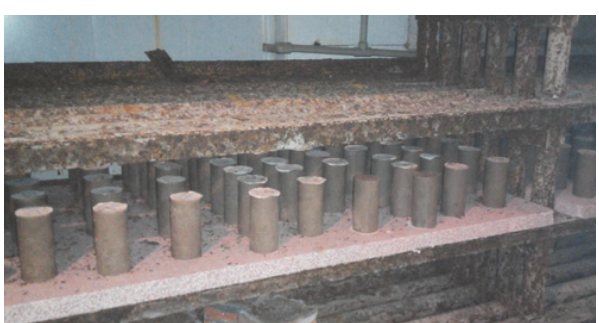

Figure 2: Mixture example with basalt fibre and cement-soil.

with a metallic colour and had three different lengths: $6 \mathrm{~mm}$, $12 \mathrm{~mm}$, and $18 \mathrm{~mm}$. Physical indices of the soft soil, cement, and basalt fibre are, respectively, shown in Tables 1, 2, and 3.

The preparation and curing processes were as follows:

(a) Dry and smash the mucky silty clay, filter the soil with a $2 \mathrm{~mm}$-bore-diameter filter sieve, and test its moisture content.

(b) Mix the soil and basalt fibre, and stir evenly; recover the moisture content of the soil based on the natural moisture content, which was $36 \%$ in this study, and seal the mixed fibre soil in a hermetic bag to avoid evaporation for $24 \mathrm{~h}$.

(c) Mix the fibre soil and cement paste in which the mass ratio of water and cement is 0.5 and stir evenly. Weigh the mixture sample and divide the weight into four equal parts by weight. Use the sample kit to manufacture the sample and divide the vibratory compaction into four layers using the four divided weights, respectively. The prepared sample can be seen in Figure 2 and the size was $\emptyset 50$ h100.

(d) Cool it for $24 \mathrm{~h}$ before forming the stripping, test its mass, and dispose of any sample whose weight is greater than $20 \%$ of the average. Number the samples, and place them in the curing room in which the relative humidity is greater than $95 \%$ and the temperature is $20 \pm 3^{\circ} \mathrm{C}$. Samples were divided into three groups by three ages, and each group included six parallel samples in this study.

(e) One day before the expired age, remove the sample from the curing room to underwater maintenance for $24 \mathrm{~h}$.

2.2. Test Scheme and Method. An orthogonal test scheme was used considering the factors of the basalt fibre content, basalt fibre length, and mixing amount of cement. The ratios of the test materials are shown in Table 4, in which the fibre content is the mass ratio of the fibre to dry soil. Each group prepared 6 samples, and there were 21 groups with 756 samples in total.

2.2.1. Unconfined Compressive Strength Test. The mixing pile in a horizontal loading would suffer unidirectional compressive stress. An unconfined compressive strength test was conducted to evaluate the compression resistance of the cement-soil. The test method refers to the assay method 
TABLE 1: The physical and mechanical indices of soft soil.

\begin{tabular}{|c|c|c|c|c|c|c|c|c|c|c|}
\hline \multirow{3}{*}{ Index } & \multirow{2}{*}{ Natural moisture } & \multirow{2}{*}{ Weight } & \multirow{2}{*}{ Void ratio } & \multirow{2}{*}{ Saturability } & \multirow{2}{*}{ Liquid limit } & \multirow{2}{*}{ Plastic limit } & \multirow{2}{*}{ Plastic index } & \multicolumn{3}{|c|}{ Statistical results of grain size } \\
\hline & & & & & & & & $0.25 \sim 0.075$ & $0.075 \sim 0.005$ & $<0.005$ \\
\hline & $W / \%$ & $/ \mathrm{kN} \cdot \mathrm{m}^{-3}$ & $e$ & $S_{r} / \%$ & $W_{L} / \%$ & $W_{P} / \%$ & $I_{P}$ & & $\%$ & \\
\hline Values & 36.2 & 18.0 & 1.014 & 96 & 33.8 & 22.9 & 10.9 & $3.7 \%$ & $85.5 \%$ & $10.8 \%$ \\
\hline
\end{tabular}

TABLE 2: The basic parameters of cement.

\begin{tabular}{|c|c|c|c|c|c|c|c|c|c|}
\hline \multirow{2}{*}{ Cement } & \multirow{2}{*}{$\begin{array}{c}\mathrm{SO}_{3} \\
1 \%\end{array}$} & \multirow{2}{*}{$\begin{array}{l}\mathrm{MgO} \\
/ \%\end{array}$} & \multirow{2}{*}{$\begin{array}{l}\mathrm{Cl}^{-} \\
1 \%\end{array}$} & \multirow{2}{*}{$\begin{array}{l}\text { Initial setting } \\
\text { time/min }\end{array}$} & \multirow{2}{*}{$\begin{array}{l}\text { Final setting } \\
\text { time/min }\end{array}$} & \multicolumn{2}{|c|}{ Rupture strength/MPa } & \multicolumn{2}{|c|}{ Rupture strength/MPa } \\
\hline & & & & & & $3 \mathrm{~d}$ & $28 \mathrm{~d}$ & $3 \mathrm{~d}$ & $28 \mathrm{~d}$ \\
\hline P.C 32.5 & $\leq 3.5$ & $\leq 6.0$ & $\leq 0.06$ & $\geq 45$ & $\leq 600$ & $\geq 2.5$ & $\geq 5.5$ & $\geq 10$ & $\geq 32.5$ \\
\hline
\end{tabular}

TABLE 3: The performance parameters of basalt fibre.

\begin{tabular}{lccccc}
\hline Type & Density $/\left(\mathrm{kg} / \mathrm{m}^{3}\right)$ & $\begin{array}{c}\text { Tensile } \\
\text { strength/MPa }\end{array}$ & $\begin{array}{c}\text { Elastic modulus } \\
/ \mathrm{GPa}\end{array}$ & $\begin{array}{c}\text { Acid-base } \\
\text { resistance } \\
\text { property }\end{array}$ & $\begin{array}{c}\text { Melting } \\
\text { point } /{ }^{\circ} \mathrm{C}\end{array}$ \\
$\begin{array}{l}\text { Bunchy } \\
\text { monofilament }\end{array}$ & 2650 & $\geq 2000$ & $90 \sim 110$ & $\geq 99 \%$ & 1250 \\
\hline
\end{tabular}

TABLE 4: The ratio of test materials.

\begin{tabular}{|c|c|c|c|c|c|c|c|}
\hline \multirow{2}{*}{ Number } & \multirow{2}{*}{ Cement mixing ratio/\% } & \multirow{2}{*}{ Water cement ratio } & \multirow{2}{*}{ Fibre content $/ \%$} & \multirow{2}{*}{ Fibre length/mm } & \multicolumn{3}{|c|}{ Age } \\
\hline & & & & & $7 \mathrm{~d}$ & $28 \mathrm{~d}$ & $90 \mathrm{~d}$ \\
\hline $\mathrm{C} 18 \%$ & 18 & 0.5 & 0 & 0 & 6 & 6 & 6 \\
\hline $\mathrm{C} 15 \%$ & 15 & 0.5 & 0 & 0 & 6 & 6 & 6 \\
\hline B0.2\% & 15 & 0.5 & 0.2 & 12 & 6 & 6 & 6 \\
\hline B $0.4 \%$ & 15 & 0.5 & 0.4 & 12 & 6 & 6 & 6 \\
\hline В0.6\% & 15 & 0.5 & 0.6 & 12 & 6 & 6 & 6 \\
\hline B6 mm & 15 & 0.5 & 0.4 & 6 & 6 & 6 & 6 \\
\hline B24 mm & 15 & 0.5 & 0.4 & 24 & 6 & 6 & 6 \\
\hline
\end{tabular}

$\mathrm{C}$ is the abbreviation of cement; $\mathrm{B}$ is the abbreviation of basalt fibre.

of concrete. In the process of the test, the pressure should be uniform, the sample should be kept on the centre axis of the pressure plate, and the head face should be parallel to the pressure-bearing surface and the top loading board. The testing machine was acquired from Bert Industry \& Trade Co., LTD, in Jinan city, China. The loading rate was $8 \mathrm{~mm} / \mathrm{min}$, and the test was stopped when the stress reached a stage of rapid decreases.

In the test, if the compressive strength of the 6 samples in one group is not larger than $15 \%$ of the average value, the average value is taken as the compressive strength. If the strength value is larger than $20 \%$ of the average, the average value of the middle four samples is taken as the compressive strength. If the compressive strength of the middle four samples is also larger than $20 \%$ of average, the test of this group is considered to be invalid.

Unconfined compressive strength can be obtained from

$$
f_{\mathrm{cu}}=\frac{P}{A}
$$

where $f_{\mathrm{cu}}$ is the unconfined compressive strength, MPa; $P$ is the failure loading, $\mathrm{kN}$; and $A$ is the cross-sectional area of the sample.

2.2.2. Tensile Splitting Strength Test. While bearing a horizontal loading, the pile would suffer from tensile stress. A tensile splitting strength test was conducted to calculate the tensile strength of the samples. Before the test, the position of the splitting line should be determined, and the split line should be consistent with the centre line at the bottom of the pressure plate. When the pressure attenuates quickly after the peak value, the test is ended, and the peak pressure as the failure load is recorded. In the test, the loading rate was $8 \mathrm{~mm} / \mathrm{min}$, and the precision of strength can reach $0.01 \mathrm{kN}$.

The tensile strength can be obtained from

$$
\sigma_{t}=\frac{2 P}{\pi d l},
$$


TABLE 5: The unconfined compressive strength.

\begin{tabular}{|c|c|c|c|c|c|c|}
\hline Sample & $\begin{array}{c}7 \mathrm{~d} \\
\text { compressive } \\
\text { strength/MPa }\end{array}$ & $\begin{array}{l}\text { Variable } \\
\text { coefficient }\end{array}$ & $\begin{array}{c}28 \mathrm{~d} \\
\text { compressive } \\
\text { strength/MPa }\end{array}$ & $\begin{array}{c}\text { Variable } \\
\text { coefficient }\end{array}$ & $\begin{array}{c}90 \mathrm{~d} \\
\text { compressive } \\
\text { strength/MPa }\end{array}$ & $\begin{array}{c}\text { Variable } \\
\text { coefficient }\end{array}$ \\
\hline $\mathrm{C} 18 \%$ & 1.08 & 0.01 & 1.52 & 0.04 & 2.28 & 0.07 \\
\hline $\mathrm{C} 15 \%$ & 1.03 & 0.03 & 1.29 & 0.05 & 1.90 & 0.02 \\
\hline B0.2\% & 1.08 & 0.04 & 1.58 & 0.09 & 2.31 & 0.01 \\
\hline B0.4\% & 1.16 & 0.03 & 1.67 & 0.03 & 2.43 & 0.07 \\
\hline B0.6\% & 1.14 & 0.01 & 1.62 & 0.01 & 2.38 & 0.01 \\
\hline $\mathrm{B} 6 \mathrm{~mm}$ & 1.12 & 0.08 & 1.54 & 0.03 & 2.40 & 0.04 \\
\hline $\mathrm{B} 24 \mathrm{~mm}$ & 1.09 & 0.01 & 1.51 & 0.07 & 2.18 & 0.07 \\
\hline
\end{tabular}

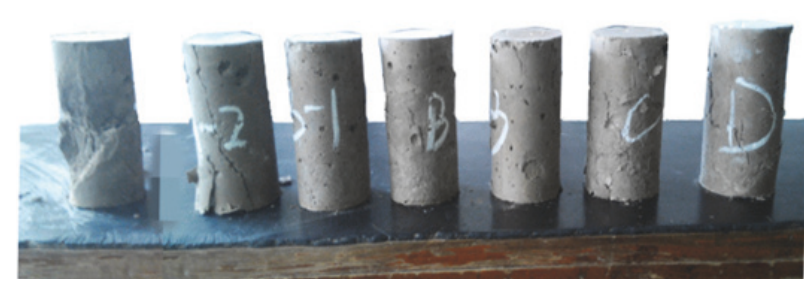

(a) Unconfined compression

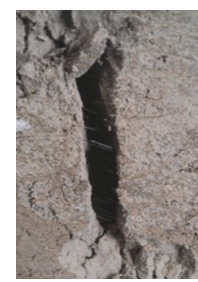

(b) Tensile splitting

FIGURE 3: Failure modes of the unconfined compression test and tensile splitting test.

where $\sigma_{t}$ is the tensile strength, MPa; $P$ is the failure load, $\mathrm{kN}$; $d$ is diameter of the sample, $\mathrm{mm}$; and $l$ is height of the sample, $\mathrm{mm}$.

\subsubsection{Triaxial Shear Strength Test. While bearing a horizontal} loading, the pile would suffer from shear stress. A triaxial shear strength test was conducted to determine the strength of the pile. The test using the UU shear test refers to the shear strength test of the concrete. In the test, the American GCTS static dynamic triaxial test apparatus was used with an HCA-300 static triaxial test module. The axial strain rate was controlled at $1 \% / \mathrm{min}$ and the axial strain value was recorded every $0.5 \%$ of axial strain. The test concluded when the axial strain reached $15 \%$. Four types of confining pressures were taken at $100 \mathrm{kPa}, 200 \mathrm{kPa}, 300 \mathrm{kPa}$, and $400 \mathrm{kPa}$.

\subsection{Unconfined Compressive Strength}

2.3.1. Failure Characteristics. Figure 3(a) shows the failure characteristics under unconfined compression. The sample numbers from left to right are $\mathrm{C} 15 \%$ and $\mathrm{C} 18 \%, \mathrm{~B} 0.2 \%$, $\mathrm{B} 0.4 \%, \mathrm{~B} 0.6 \%, \mathrm{~B} 6 \mathrm{~mm}$, and $\mathrm{B} 24 \mathrm{~mm}$. The failure patterns of the plain cement-soil samples are indicative of the brittle characteristics, as the failure crack is small and thin and only a small fraction separated from the sample. This illustrates that the fibre length has an impact on the compressive failure pattern.

2.3.2. Basalt Fibre Content. The unconfined compressive strengths of plain cement-soil and cement-soil reinforced by

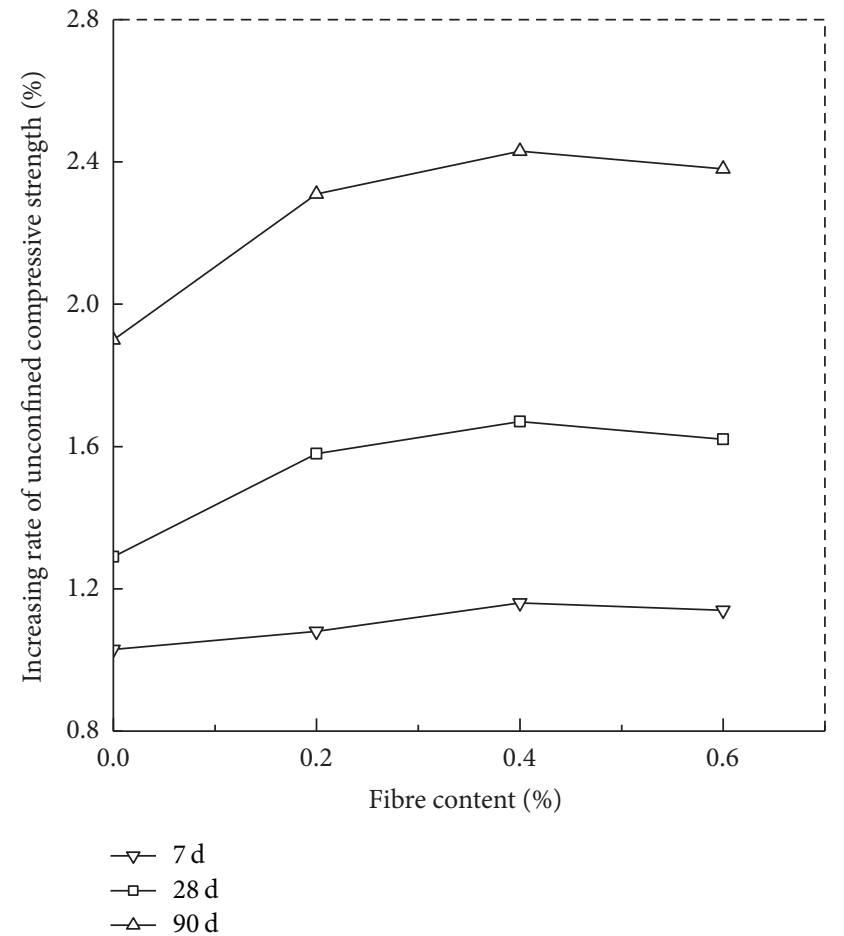

FIgURE 4: The relations of fibre content and strength.

basalt fibre of three different ages and fibre content are shown in Table 5. The relationship between the basalt fibre content and compressive strength is observed in Figure 4, in which 
TABLE 6: The tensile strength of basalt fibre samples.

\begin{tabular}{|c|c|c|c|c|c|c|}
\hline Sample & $\begin{array}{c}7 \mathrm{~d} \text { tensile } \\
\text { strength/MPa }\end{array}$ & $\begin{array}{c}\text { Variable } \\
\text { coefficient }\end{array}$ & $\begin{array}{c}28 \mathrm{~d} \text { tensile } \\
\text { strength } / \mathrm{MPa}\end{array}$ & $\begin{array}{c}\text { Variable } \\
\text { coefficient }\end{array}$ & $\begin{array}{c}90 \mathrm{~d} \text { tensile } \\
\text { strength/MPa }\end{array}$ & $\begin{array}{c}\text { Variable } \\
\text { coefficient }\end{array}$ \\
\hline C18\% & 0.24 & 0.03 & 0.36 & 0.03 & 0.60 & 0.08 \\
\hline $\mathrm{C} 15 \%$ & 0.20 & 0.01 & 0.28 & 0.03 & 0.45 & 0.05 \\
\hline B0.2\% & 0.23 & 0.01 & 0.34 & 0.09 & 0.58 & 0.01 \\
\hline B0.4\% & 0.29 & 0.04 & 0.42 & 0.08 & 0.66 & 0.05 \\
\hline B0.6\% & 0.25 & 0.07 & 0.39 & 0.02 & 0.59 & 0.03 \\
\hline B6 mm & 0.27 & 0.02 & 0.37 & 0.01 & 0.56 & 0.05 \\
\hline B24 mm & 0.25 & 0.08 & 0.38 & 0.05 & 0.54 & 0.07 \\
\hline
\end{tabular}

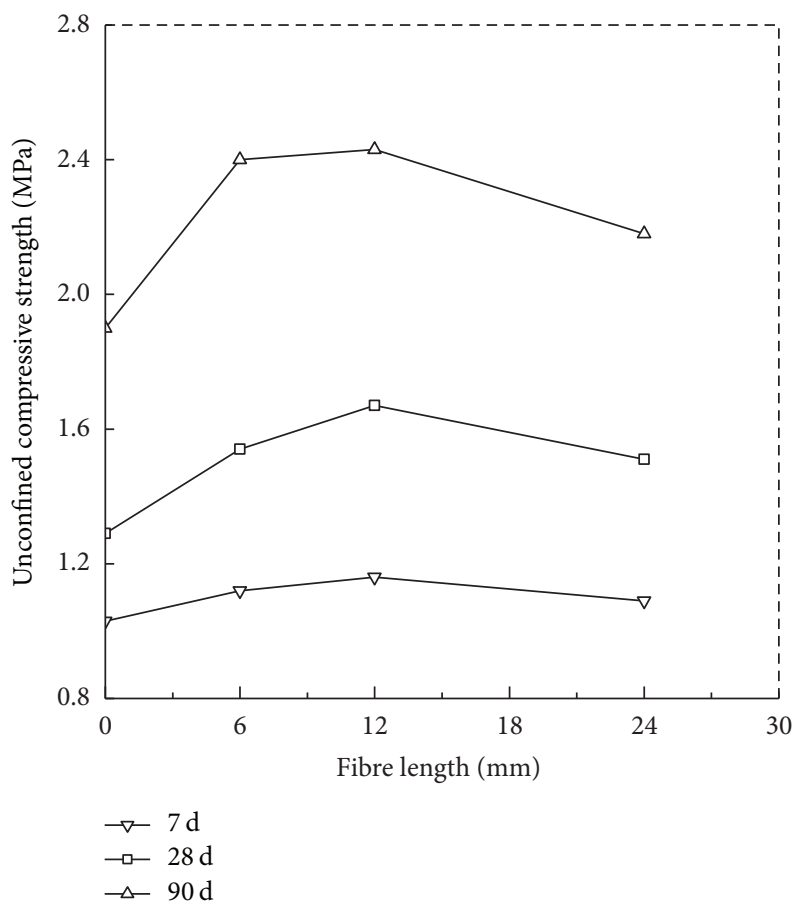

FIgURE 5: The relations of fibre length and strength.

the cement content is $15 \%$, the fibre length is $12 \mathrm{~mm}$, and the fibre contents are $0.2 \%, 0.4 \%$, and $0.6 \%$, respectively. As seen from Table 5 and Figure 4, the unconfined compressive strength of the cement-soil reinforced by basalt fibre is larger than that of the plain cement-soil by $20 \% \sim 30 \%$. With an increase in the basalt fibre content, the unconfined compressive strength first increased but then slowly decreased. The optimal amount of basalt fibre is given at the peak, which had a value of $0.4 \%$.

2.3.3. Basalt Fibre Length. The relationship between the basalt fibre length and the unconfined compressive strength can be determined from Figure 5. It was observed that, with an increase in the fibre length, the unconfined compressive strength present increased first and then decreased, giving a peak value at $12 \mathrm{~mm}$.

2.3.4. 3D Enveloping Surface of the Unconfined Compressive Strength. Figure 6(a) shows the 3D enveloping surface of the unconfined compressive strength when the curing periods are 7 and $28 \mathrm{~d}$. The sensitivity of the basalt fibre length impacting the unconfined compressive strength is larger than that of the sample curing at $90 \mathrm{~d}$. The strength shows increasing first and then decreasing, with a peak value at $12 \mathrm{~mm}$. When the curing period is $90 \mathrm{~d}$, the fitting surface appeared to have a "hog" characteristic, as the unconfined compressive strength increased significantly when the fibre content was more than $0.2 \%$, and the peak value appeared at a fibre content of $0.4 \%$, after which the peak value of the unconfined compressive strength gradually decreased. Therefore, the basalt fibre content and length both have an impact on the unconfined compressive strength.

\subsection{Tensile Splitting Strength}

2.4.1. Failure Characteristics. Figure 3(b) shows the failure characteristics of the tensile splitting test. The amount of basalt fibre was vertically distributed in the cracking surface, which illustrates that the basalt fibre plays an inhibiting role in the tensile deformation.

2.4.2. Basalt Fibre Content. The tensile strengths of the plain cement-soil and cement-soil reinforced by basalt fibre are shown in Table 6 . The relationship between the basalt fibre content and the tensile strength can be determined from Figure 7. As seen from Table 6 and Figure 7, the tensile strength of the cement-soil reinforced by basalt fibre is larger than that of the plain cement-soil. The tensile strength of sample B0.4\% when the curing period is $28 \mathrm{~d}$ increases by $50 \%$. The same curing periods with an increased basalt fibre content increased the rate of tensile strength by increasing first and then decreasing, with a peak value appearing at a basalt fibre content of $0.4 \%$. Therefore, the increasing basalt fibre content can effectively improve the splitting tensile strength, and the optimal basalt fibre content was found to be $0.4 \%$.

2.4.3. Basalt Fibre Length. The relationship between the basalt fibre length and the tensile strength can be determined from Figure 8. It was observed that the length of the fibre had a significant impact on the tensile splitting strength of the cement-soil. With the same curing period, increasing the fibre length increased the rate of the tensile strength 


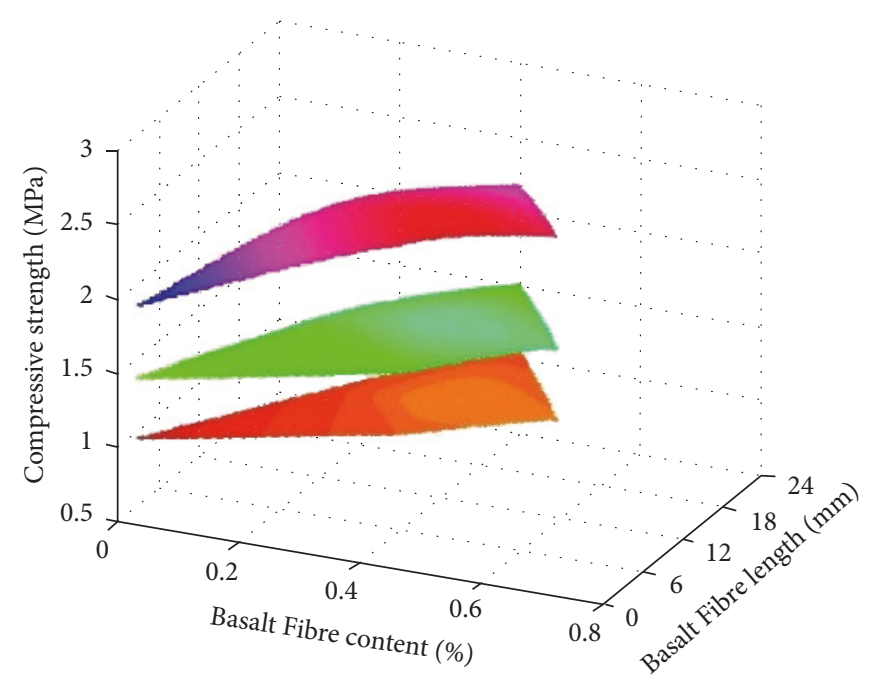

(a) Unconfined compression

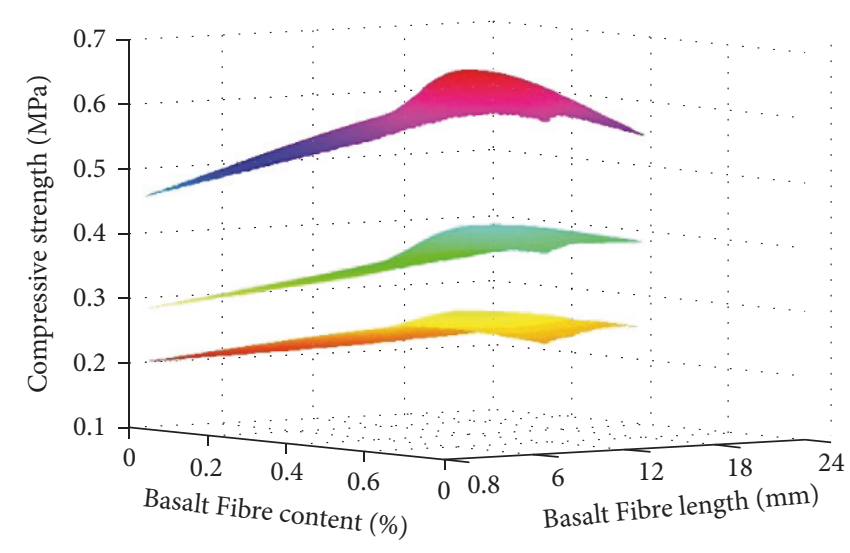

(b) Tensile splitting

FIgURE 6: The 3D envelope surface of the compressive strength and tensile strength.

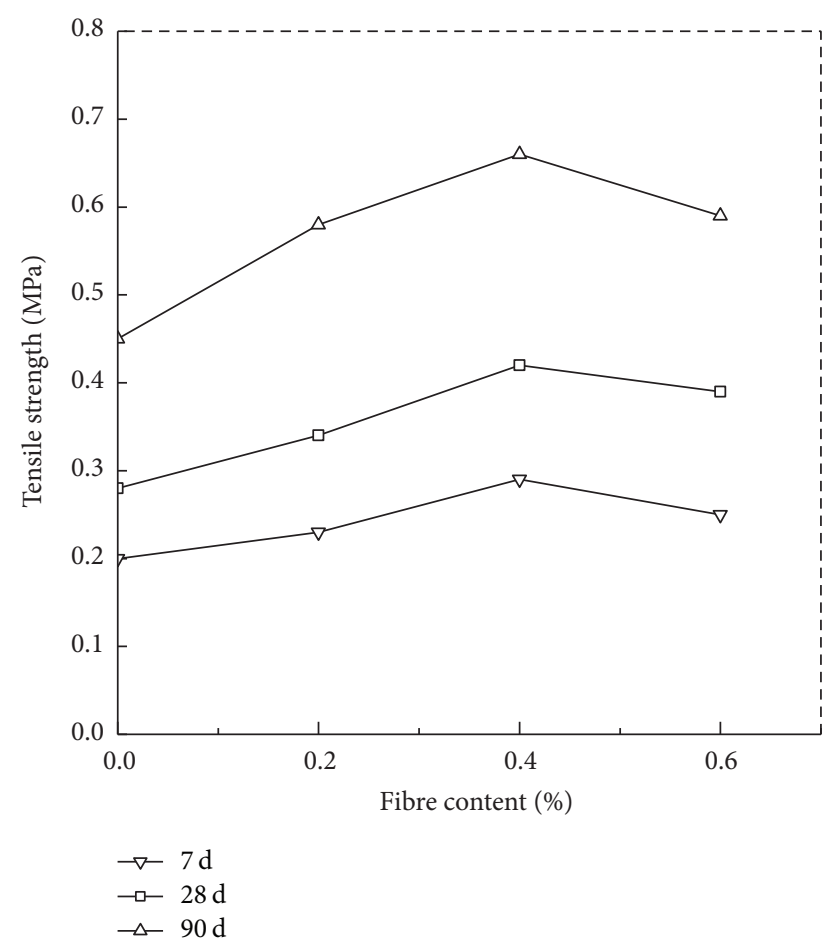

FIGURE 7: The relations of fibre content and strength.

by increasing first and then decreasing, with the peak value appearing at $12 \mathrm{~mm}$.

2.4.4. 3D Enveloping Surface of the Tensile Splitting Strength. Figure 6(b) shows the 3D enveloping surface for the tensile splitting strength. Each of the three fitting surfaces had an extreme value. With increases in the basalt fibre content and length, the tensile strength increased first and then decreased, with a peak value at $0.2 \%$ when the basalt fibre length is

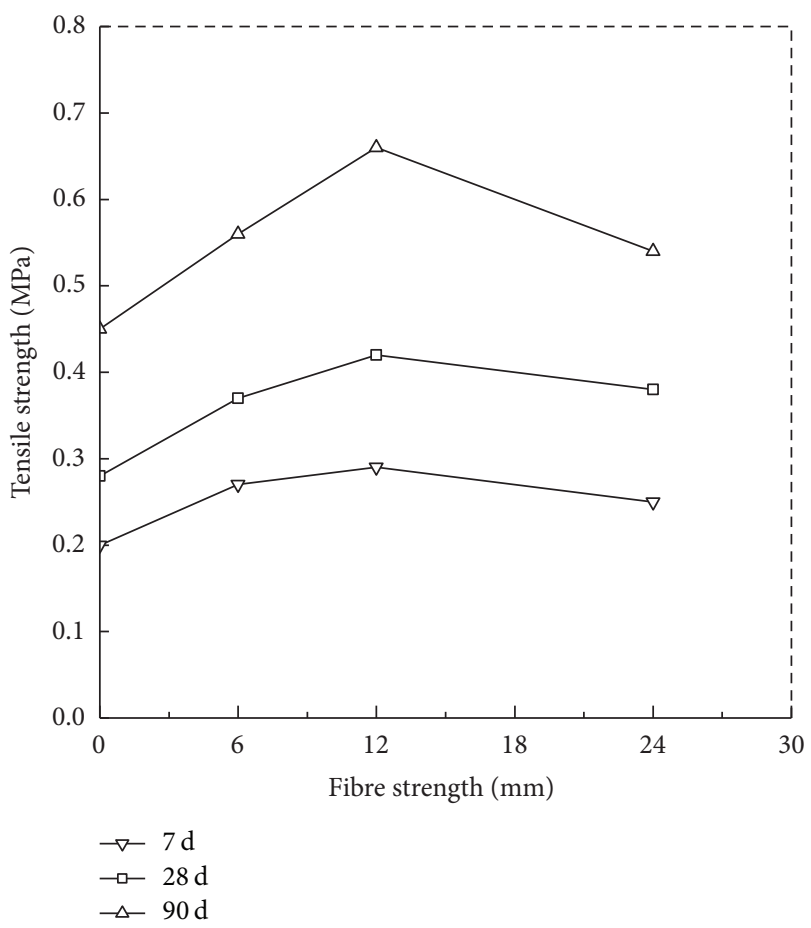

Figure 8: The relations of fibre length and strength.

longer than $6 \mathrm{~mm}$. The enveloping surface revealed a hump phenomenon, with the peak value appearing at a basalt content of $0.4 \%$ and a basalt fibre length of $12 \mathrm{~mm}$.

\subsection{Triaxial Shear Strength}

2.5.1. Shear Strain. The stress-strain curves of the plain cement-soil samples and cement-soil samples reinforced by basalt fibre under different confining pressures are shown 


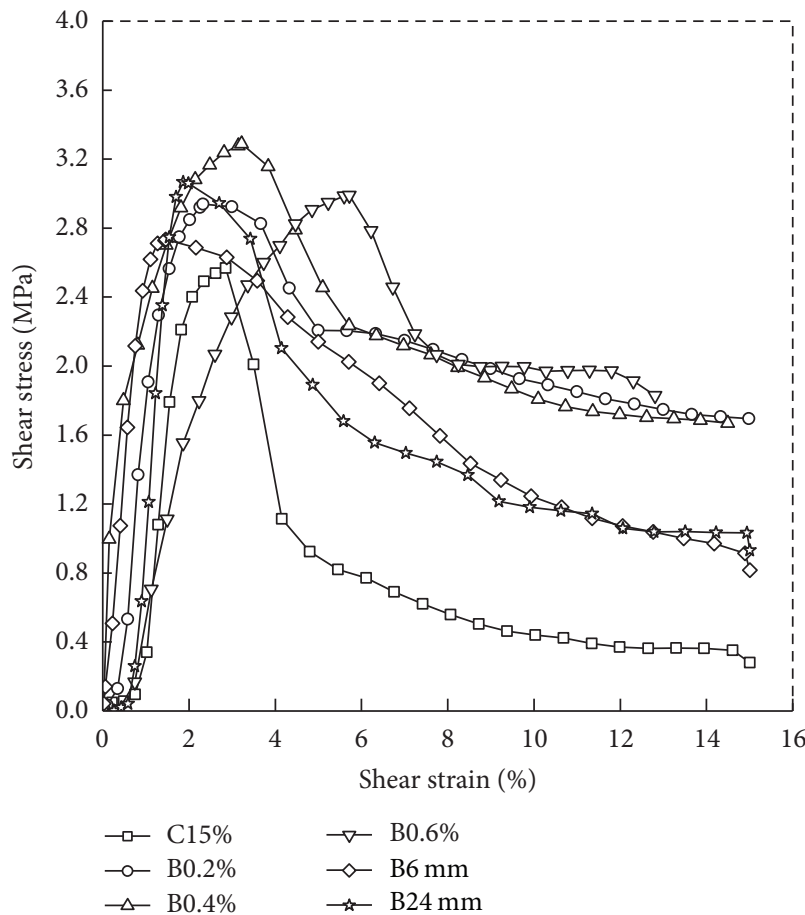

(a) Curing age $28 \mathrm{~d}$, confining pressure $100 \mathrm{kPa}$

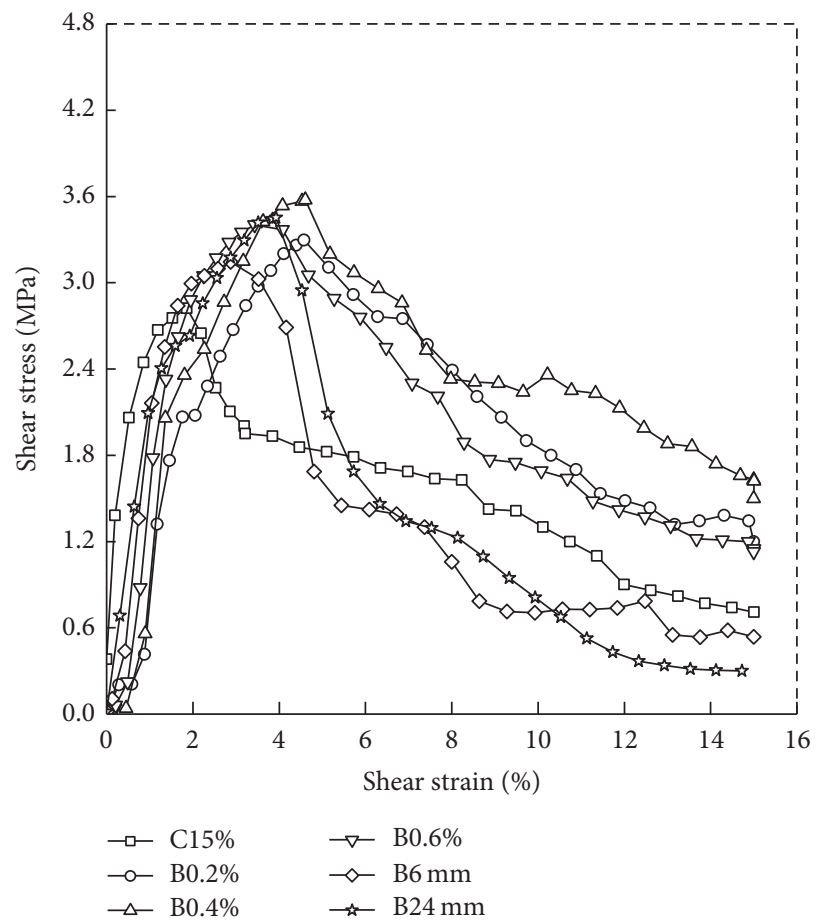

(c) Curing age $28 \mathrm{~d}$, confining pressure $300 \mathrm{kPa}$

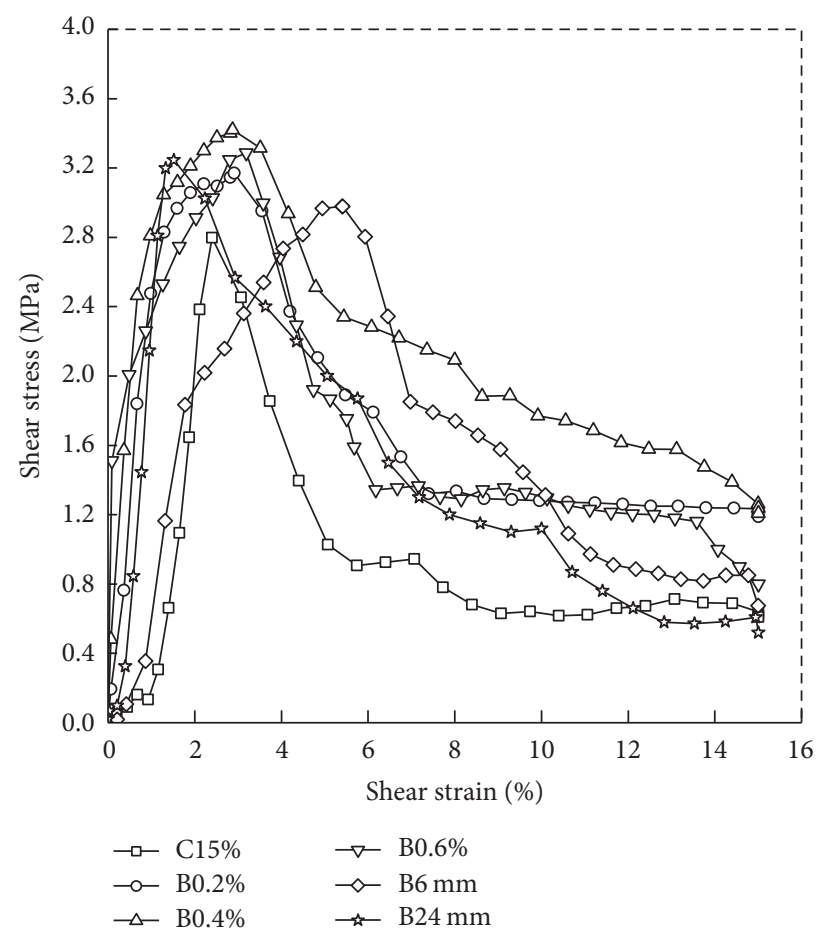

(b) Curing age $28 \mathrm{~d}$, confining pressure $200 \mathrm{kPa}$

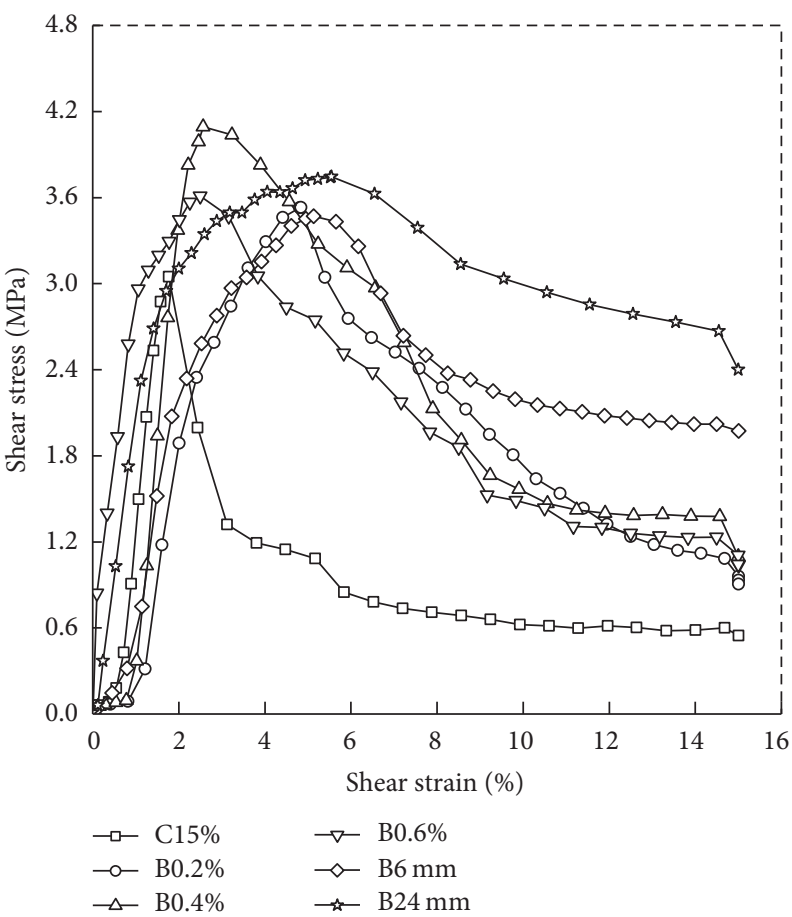

(d) Curing age $28 \mathrm{~d}$, confining pressure $400 \mathrm{kPa}$

FIGURE 9: The curves of shear stress and shear strain after curing for 28 days.

for the specific case of the $28 \mathrm{~d}$ samples and are shown in Figure 9 with the failure parameters shown in Table 7. As seen in Figure 9 and Table 7, the peak value of the primary stress difference for the reinforced cement-soil is significantly larger than the plain cement-soil, and the plain cement-soil showed a brittle failure, while the reinforced cement-soil significantly inhibited brittle failure. The failure stress of sample B0.4\% had a higher stress level than the other samples, and the stress after peak value occurred at higher stress levels. The failure stress and strain of samples B6 mm and B24 mm under 
TABLE 7: Related parameters of shear stress and shear strain after 28 days.

\begin{tabular}{|c|c|c|c|c|c|c|c|}
\hline $\begin{array}{l}\text { Confining } \\
\text { pressure/kPa }\end{array}$ & Parameters & $\mathrm{C} 15 \%$ & B0.2\% & B0.4\% & B0.6\% & $\mathrm{B} 6 \mathrm{~mm}$ & $\mathrm{~B} 24 \mathrm{~mm}$ \\
\hline \multirow{3}{*}{100} & $\begin{array}{c}\text { Failure } \\
\text { strength/MPa }\end{array}$ & 2.55 & 2.95 & 3.20 & 3.01 & 2.71 & 3.07 \\
\hline & Failure strain/\% & 1.55 & 2.32 & 3.22 & 5.72 & 1.46 & 1.87 \\
\hline & $P_{15 \%} / \mathrm{MPa}$ & 0.28 & 1.69 & 1.67 & 1.82 & 0.82 & 0.93 \\
\hline \multirow{3}{*}{200} & $\begin{array}{c}\text { Failure } \\
\text { strength/MPa }\end{array}$ & 2.78 & 3.15 & 3.42 & 3.27 & 2.97 & 3.23 \\
\hline & Failure strain/\% & 2.40 & 2.91 & 3.14 & 3.19 & 5.40 & 1.52 \\
\hline & $P_{15 \%} / \mathrm{MPa}$ & 0.61 & 1.19 & 1.20 & 1.16 & 0.82 & 0.51 \\
\hline \multirow{3}{*}{300} & $\begin{array}{c}\text { Failure } \\
\text { strength/MPa }\end{array}$ & 2.82 & 3.30 & 3.63 & 3.39 & 3.13 & 3.44 \\
\hline & Failure strain/\% & 1.86 & 4.57 & 4.63 & 3.43 & 2.88 & 3.92 \\
\hline & $P_{15 \%} / \mathrm{MPa}$ & 0.74 & 1.2 & 1.62 & 1.15 & 0.54 & 0.30 \\
\hline \multirow{3}{*}{400} & $\begin{array}{c}\text { Failure } \\
\text { strength/MPa }\end{array}$ & 3.02 & 3.51 & 4.07 & 3.65 & 3.47 & 3.74 \\
\hline & Failure strain/\% & 1.77 & 4.84 & 3.90 & 2.50 & 5.13 & 5.55 \\
\hline & $P_{15 \%} / \mathrm{MPa}$ & 0.55 & 0.90 & 1.39 & 1.04 & 1.97 & 2.40 \\
\hline
\end{tabular}

confining stresses of $100 \mathrm{kPa}$ and $200 \mathrm{kPa}$ are lower than the plain cement-soil sample $\mathrm{C} 15 \%$, and the failure stresses all occur at higher stress levels when the confining stress is $300 \mathrm{kPa}$.

2.5.2. Basalt Fibre Content. The shear strengths of the samples for different curing ages and different confining stresses are shown in Table 8 , and the shear strength parameters of the cement-soil reinforced by basalt fibre for different curing ages are shown in Table 9. The relationship between the basalt fibre content and shear strength is shown in Figure 10. As seen from Tables 8 and 9 and Figure 10, with increases in the fibre content, the shear strength, cohesive force, and internal friction angle all increased first and then decreased, with a peak value appearing at a basalt fibre content of $0.4 \%$. In addition, the cohesive force impacted by the basalt fibre content is more sensitive than the internal friction angle.

2.5.3. Basalt Fibre Length. The relationship between the basalt fibre length and the shear strength can be observed from Figure 11, which shows that the shear strength and cohesive force both exhibit an increase first and then decrease with an increasing of the basalt fibre length, and a peak value appears at $12 \mathrm{~mm}$. The sensibility of the fibre length impacting the strength parameters is similar to that of the basalt fibre content.

2.6. The Optimal Ratio of Materials. From the performed tests, the mass component of the materials to fabricate a mixing pile can be formed by basalt fibre 0.4 , cement 15 , water 7.5 , and mucky soil 0.02 , with an optimal ratio of basalt fibre content of $0.4 \%$ and an optimal length of $12 \mathrm{~mm}$. By mixing the basalt fibre in cement-soil, the unconfined compressive

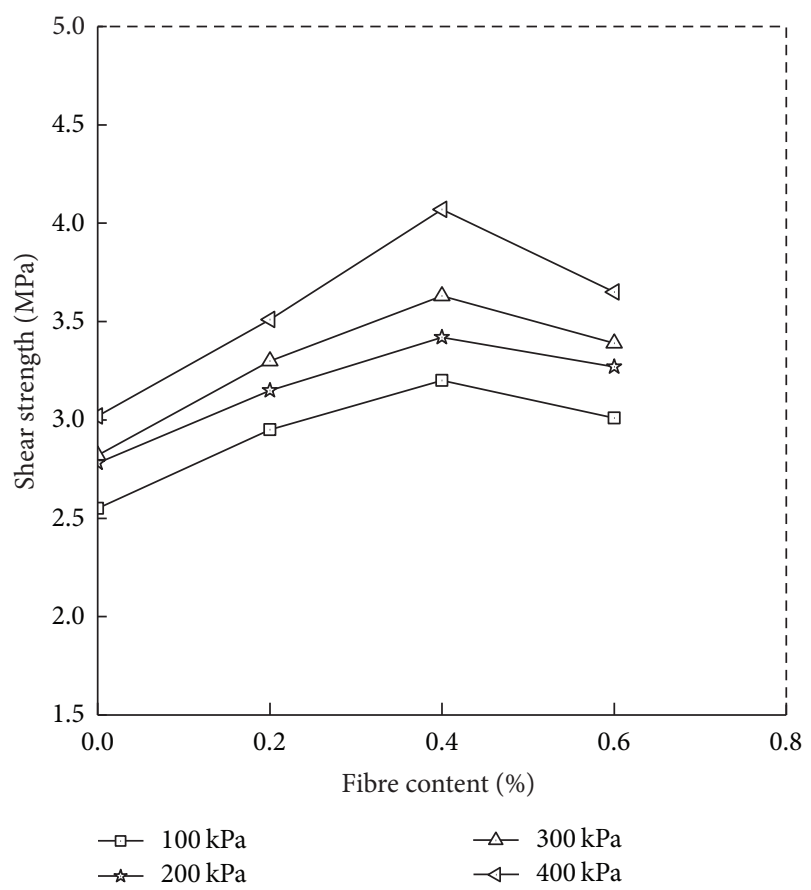

FIGURE 10: The relationship between fibre content and sample strength.

strength increased by $26.3 \%$, the splitting tensile strength increased by $50 \%$, and the shear strength increased by $33 \%$.

\section{Construction Technology}

In the process of construction technology, only basalt fibre that is uniformly dispersed in the cement-soil mixing pile body can effectively improve the performance regarding the 
TABLE 8: The data of the shear strength test.

\begin{tabular}{|c|c|c|c|c|c|c|c|c|}
\hline \multirow{2}{*}{ Age/d } & \multirow{2}{*}{ Confining pressure $/ \mathrm{kPa}$} & \multicolumn{7}{|c|}{ Shear strength/MPa } \\
\hline & & $\mathrm{C} 18 \%$ & $\mathrm{C} 15 \%$ & B0.2\% & B0.4\% & B0.6\% & $\mathrm{B} 6 \mathrm{~mm}$ & $\mathrm{~B} 24 \mathrm{~mm}$ \\
\hline \multirow{4}{*}{7} & 100 & 2.23 & 1.89 & 2.19 & 2.45 & 2.26 & 2.35 & 2.05 \\
\hline & 200 & 2.41 & 2.01 & 2.32 & 2.82 & 2.47 & 2.36 & 2.17 \\
\hline & 300 & 2.72 & 2.16 & 2.76 & 2.98 & 2.70 & 2.54 & 2.64 \\
\hline & 400 & 3.03 & 2.44 & 3.00 & 3.26 & 2.99 & 2.90 & 2.97 \\
\hline \multirow{4}{*}{28} & 100 & 2.98 & 2.55 & 2.95 & 3.20 & 3.01 & 2.71 & 3.07 \\
\hline & 200 & 3.20 & 2.78 & 3.15 & 3.42 & 3.27 & 2.97 & 3.23 \\
\hline & 300 & 3.34 & 2.82 & 3.30 & 3.63 & 3.39 & 3.13 & 3.44 \\
\hline & 400 & 3.57 & 3.02 & 3.51 & 4.07 & 3.65 & 3.47 & 3.74 \\
\hline \multirow{4}{*}{90} & 100 & 4.31 & 3.48 & 4.39 & 4.82 & 4.61 & 4.44 & 4.38 \\
\hline & 200 & 4.76 & 4.56 & 4.70 & 5.59 & 5.33 & 4.84 & 4.79 \\
\hline & 300 & 5.01 & 4.92 & 5.04 & 5.85 & 5.74 & 5.37 & 5.32 \\
\hline & 400 & 5.82 & 5.40 & 5.96 & 6.42 & 6.09 & 5.97 & 5.87 \\
\hline
\end{tabular}

TABLE 9: Shear strength index of the cement-soil with basalt fibre reinforced for different curing times.

\begin{tabular}{|c|c|c|c|c|c|c|}
\hline \multirow{3}{*}{ Sample } & \multicolumn{5}{|c|}{ Strength parameters (cohesive force $c$, internal friction angle $\varphi$ ) } & \\
\hline & & & & & \multicolumn{2}{|c|}{$90 \mathrm{~d}$} \\
\hline & $c /(\mathrm{kPa})$ & $\varphi /\left(^{\circ}\right)$ & $c /(\mathrm{kPa})$ & $\varphi /\left(^{\circ}\right)$ & $c /(\mathrm{kPa})$ & $\varphi /\left(^{\circ}\right)$ \\
\hline $\mathrm{C} 18 \%$ & 633.7 & 24.3 & 823.5 & 26.4 & 711.5 & 36.3 \\
\hline $\mathrm{C} 15 \%$ & 478.3 & 23.0 & 725.9 & 25.3 & 686.0 & 38.7 \\
\hline B $0.2 \%$ & 644.3 & 24.5 & 822.3 & 26.6 & 954.3 & 40.3 \\
\hline B0.4\% & 665.8 & 28.2 & 916.3 & 29.8 & 1087.8 & 44.9 \\
\hline B0.6\% & 628.4 & 25.7 & 773.0 & 28.2 & 993.1 & 42.3 \\
\hline B6 mm & 597.6 & 25.2 & 824.9 & 26.7 & 837.9 & 43.1 \\
\hline B24 mm & 480.1 & 28.0 & 694.4 & 29.5 & 864.7 & 41.8 \\
\hline
\end{tabular}

horizontal stiffness and horizontal load, which is also a crucial point in applying the design practice. Direct mixing cannot achieve sufficient uniformity; therefore, yellow sand, gypsum powder, plain fill, and mucky soil as additives were considered to be used in the mixing process to help the basalt fibre distribute evenly in the cement-soil.

3.1. Mixing Process. The mass of the soil was taken as the reference quantity, and the mixing proportions of the cement and basalt fibre are $15 \%$ and $0.4 \%$ of the soil, respectively. The mass ratio of water and cement is 0.5 , and the fibre length is $12 \mathrm{~mm}$. The following processes were used in the test. As an example, the yellow sand as an additive process is shown in Figure 12.

(a) Add $50 \mathrm{~kg}$ of a tiled additive to the mixing barrel and add $1 \mathrm{~kg}$ of dry basalt fibre using a blower.

(b) Mix the additive and basalt fibre under anhydrous conditions.

(c) Add $50 \mathrm{~kg}$ of cement into the mixing barrel and mix them together.

(d) Add $25 \mathrm{~kg}$ of water and mix.

\subsection{Stirring Effect Using Different Additives}

3.2.1. Direct Mixing. A picture showing the direct mixing process is shown in Figure 13(a). The fibres easily intertwine together and precipitate, which leads to an uneven distribution. In the process of fabricating the mixing pile, basalt fibre would concentrate on some part of the pile, and the fibre would jam the stock outlet of the mixing equipment.

3.2.2. Yellow Sand as Additive. A picture showing yellow sand as the additive is shown in Figure 12(b). The basalt fibre floated in the mixture as a mass, and only limited amounts of basalt fibre and yellow sand mixed together. The fibre bundle remained unopened as filaments and would not satisfy conditions for uniform mixing.

3.2.3. Gypsum Powder as Additive. A picture showing gypsum powder as the additive is shown in Figure 13(b). The mass of gypsum powder is $2 \%$ of the basalt fibre. Since the particles of gypsum powder are small and slippery, the basalt fibre cannot readily attach to the powder. The mixture is difficult 


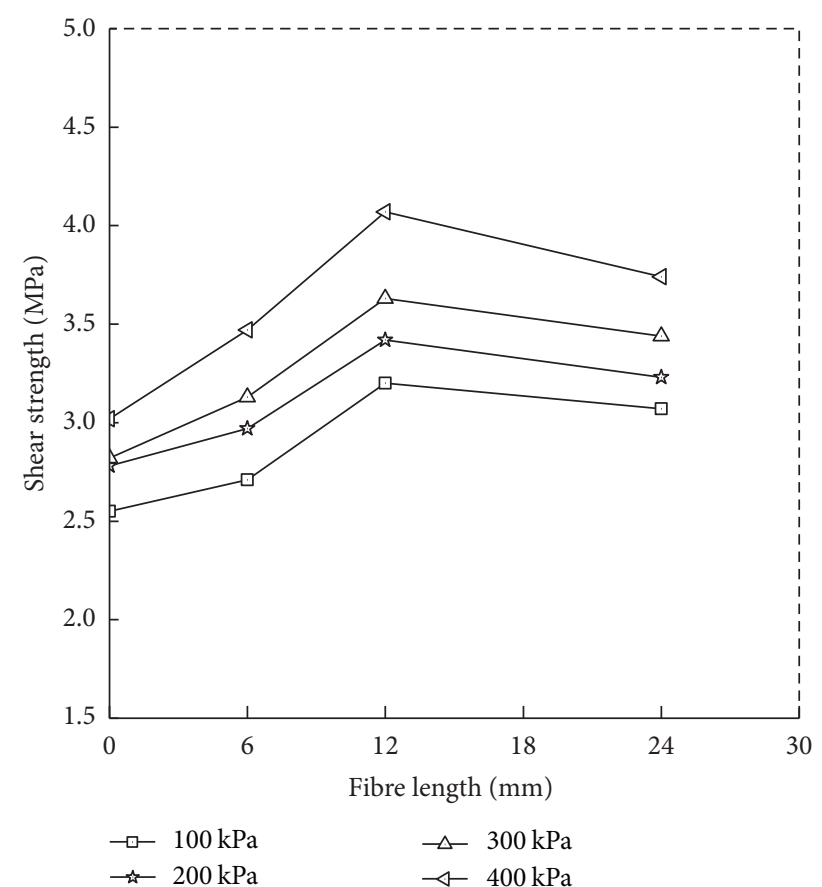

FIGURE 11: The relationship between fibre length and sample strength.

to stir evenly, and the strong water absorption capacity of gypsum powder is not conducive to mix fully.

3.2.4. Plain Fill as Additive. Pictures showing plain fill as the additive are shown in Figures 13(c) and 13(d). The mass of plain fill is $4 \%$ of the basalt fibre, the structure of the basalt fibre was slightly damaged, and after adding water, the mixed materials were flocculent. Not only is the basalt fibre not fully dispersed, but the consistency of the mixed liquor would be too thick to be applied.

3.2.5. Mucky Soil as Additive. Pictures showing mucky soil as the additive are shown in Figures 13(e) and 13(f). The mass of mucky soil is $5 \%$ of the basalt fibre. First, the mucky soil and basalt fibre were stirred together, and the soil particles adhered to the basalt fibre. Second, the configured slurry was added and mixed. After adding the slurry, the basalt fibre evenly dispersed in the mixture and had an appropriate consistency. According to the batch tests of the different additives, mucky soil was chosen as the best candidate.

3.3. Construction Technology. The mass component of the construction technological materials to create a mixing pile can be formed using basalt fibre 0.4 , cement 15 , water 7.5 , and mucky soil 0.02 , and the optimum fibre length is $12 \mathrm{~mm}$.

The procedure of the construction technology is shown as follows (Figure 14):

(a) Mix the basalt fibre and mucky soil in dry conditions using a rotary mixer. The mass ratio of basalt fibre to mucky soil is $20: 1$. (b) Stir evenly, add the cement paste into the rotary mixer, and stir evenly again. The mass ratio of the water to the cement composing cement paste is 0.5 .

(c) Locate, centre, and level the pile machine and move it to the designated spot. Centre and level it again.

(d) Adjust the perpendicularity of the guide frame using the odolite or plumbing bobs to be less than $1.0 \%$ of pile length according to the standard requirement.

(e) Premix and sink the blender into the deeper soil. Meanwhile, place the basalt fibre and cement into the aggregate bin.

(f) Start the rotary table of the mixing pile machine. When the rotation speed reaches the normal level, sink the drill pipe and stir at the same time. The sinking speed is controlled by gears.

(g) When the drill pile has been sunk to the designed depth, open the mortar pump, and when the mortar reaches the pulp mouth, start the mixing pile machine and tighten the chain device. The next procedure is guniting, stirring, and lifting the drill pile; the designed lifting speed is $0.50 \sim 0.8 \mathrm{~m} / \mathrm{min}$, yielding a fully mixed slurry and soil.

(h) When the drill bit up has been lifted to a location that is higher than the top of the pile by $500 \mathrm{~mm}$, stir and sink the drill bit into the designed depth again.

(i) Repeat the step (h) until the blender is lifted to the ground.

\section{The Verification of On-Site Test}

Site core tests of the cement-soil are conducted on the cement-soil mixing pile reinforced by basalt fibre for $90 \mathrm{~d}$.

4.1. Site Core Test. The core samples used for the strength test are collected from three random points of the whole pile length $(11 \mathrm{~m})$ using a geological drilling rig. In the process, three (double) pipes with a single-acting rotary sampler were used, and the integrity and uniformity of the core samples were checked before the mechanical test as shown in Figure 15.

4.2. Strength Contrasting of the Interior and Outdoor Test. The unconfined compressive strength tests, tensile splitting tests, and triaxial shear tests are conducted on core samples that have been soaked for $2 \mathrm{~d}$. The results are given in Table 10, in which the strength of the samples from different depths were approximately $71.2 \% \sim 77.8 \%$ that of the sample strengths obtained from indoor mixed samples. The results in general are different and generally lower than the indoor test results. Analysing the site core sample which shows the degree of uniformity and the ratio of basalt fibre may be the primary causes of the strength decreasing. The minimum compressive strength is $1.73 \mathrm{MPa}$, and the minimum tensile strength is $0.51 \mathrm{MPa}$. 
TABLE 10: Strength of core sample (90 d).

\begin{tabular}{|c|c|c|c|c|c|}
\hline \multirow{2}{*}{ Pile number } & \multirow{2}{*}{ Pile depth/m } & \multirow{2}{*}{ Compressive strength/MPa } & \multirow{2}{*}{ Tensile strength/MPa } & \multicolumn{2}{|c|}{ Shear strength } \\
\hline & & & & $c /(\mathrm{kPa})$ & $\varphi /\left(^{\circ}\right)$ \\
\hline 1 & $0.5 \sim 4.0$ & 1.73 & 0.47 & 773.9 & 42.2 \\
\hline 1 & $4.0 \sim 7.5$ & 1.83 & 0.50 & 819.2 & 43.1 \\
\hline 1 & $7.5 \sim 11.0$ & 1.80 & 0.49 & 805.8 & 42.5 \\
\hline 2 & $0.5 \sim 4.0$ & 1.75 & 0.48 & 783.4 & 42.3 \\
\hline 2 & $4.0 \sim 7.5$ & 1.78 & 0.48 & 796.8 & 42.5 \\
\hline 2 & $7.5 \sim 11.0$ & 1.89 & 0.51 & 846.1 & 43.0 \\
\hline 3 & $0.5 \sim 4.0$ & 1.75 & 0.48 & 783.4 & 42.3 \\
\hline 3 & $4.0 \sim 7.5$ & 1.78 & 0.48 & 795.2 & 42.2 \\
\hline 3 & $7.5 \sim 11.0$ & 1.86 & 0.51 & 832.6 & 43.3 \\
\hline
\end{tabular}

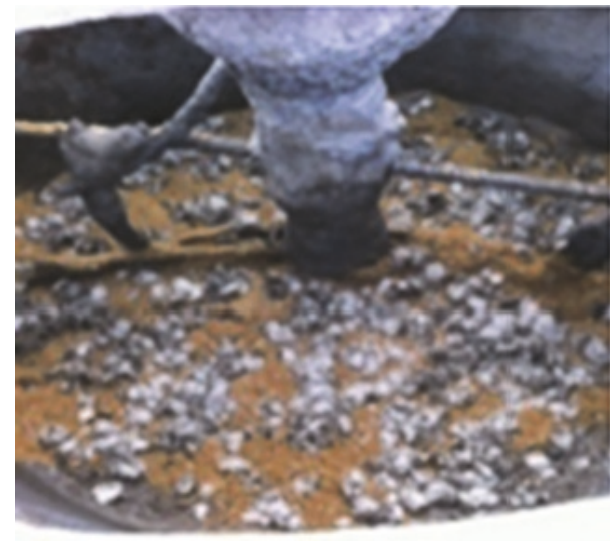

(a) Step 1

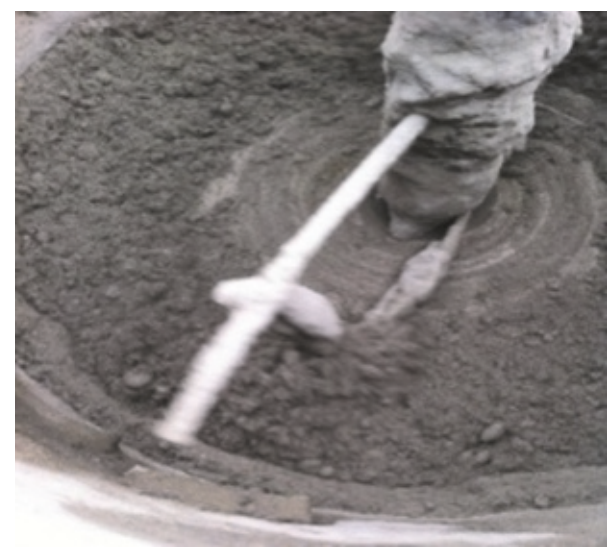

(c) Step 3

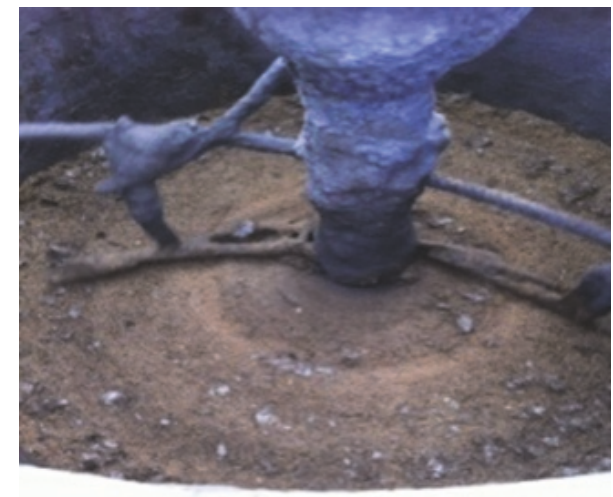

(b) Step 2

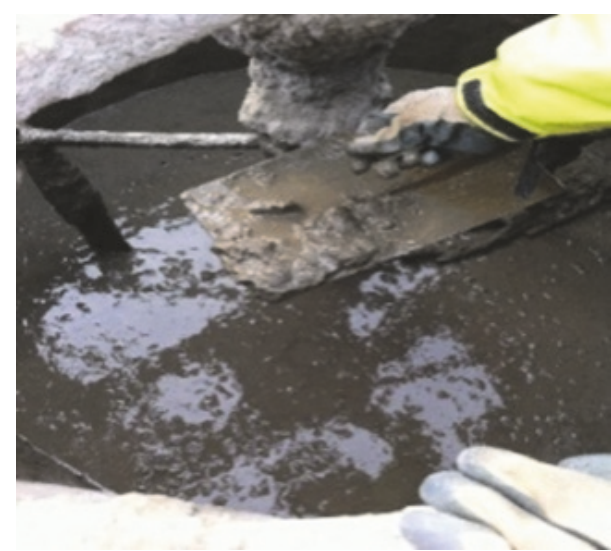

(d) Step 4

FIGURE 12: Process of mixing with a slurry blender.

\section{Discussion and Analysis}

This study aims to determine the effect of basalt fibre content, fibre length, curing age, and cement content on the cementsoil reinforcement based on the unconfined compressive strength, tensile strength, shear strength, and stress-strain characteristics and triaxial shear strength characteristics.

An appropriate basalt fibre content can effectively improve the shearing properties of cement-soil. The shear strengths of sample B0.4\% under four different confining stresses are all larger than those of samples $\mathrm{B} 0.2 \%$ and B $0.6 \%$, and the failure stress of sample B0.4\% remained at a higher level after the peak stress. Obviously, there is an optimal fibre content that produces the highest shear strength, and the residual stress remains at a relatively higher level.

As the fibre length increases, increasing rates of shear strength and cohesive force cause the strength to increase first and then decrease, with a peak value appearing at $12 \mathrm{~mm}$ for 


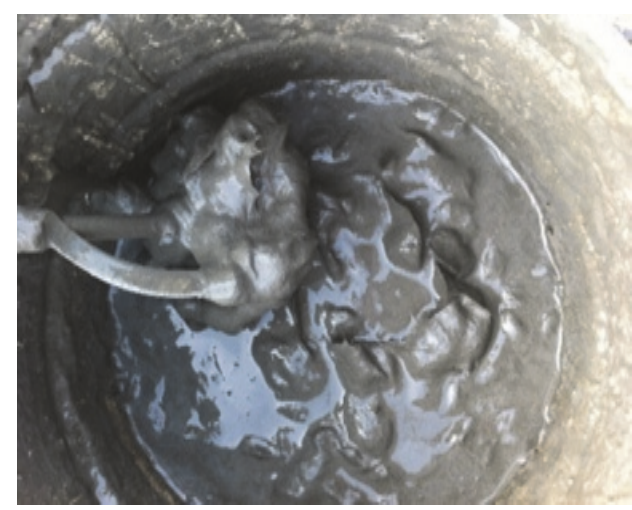

(a) Direct mixing

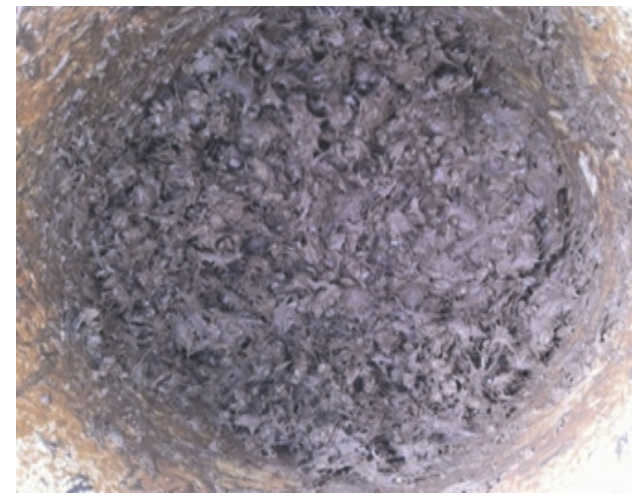

(c) Dry mixing adding plain fill

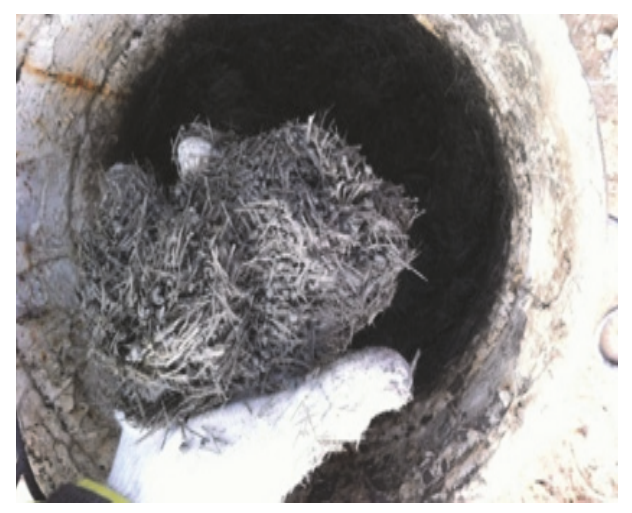

(e) Dry mixing adding mucky soil

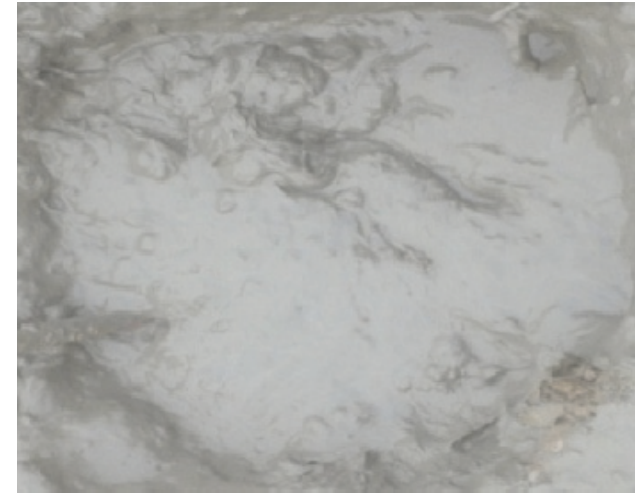

(b) Slurry mixing gypsum powder

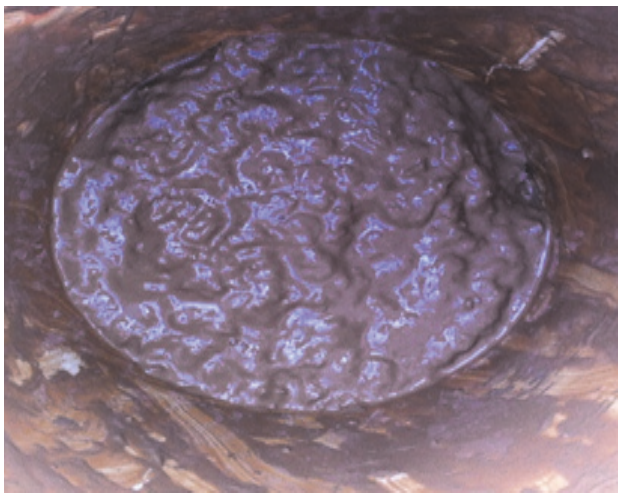

(d) Slurry mixing plain fill

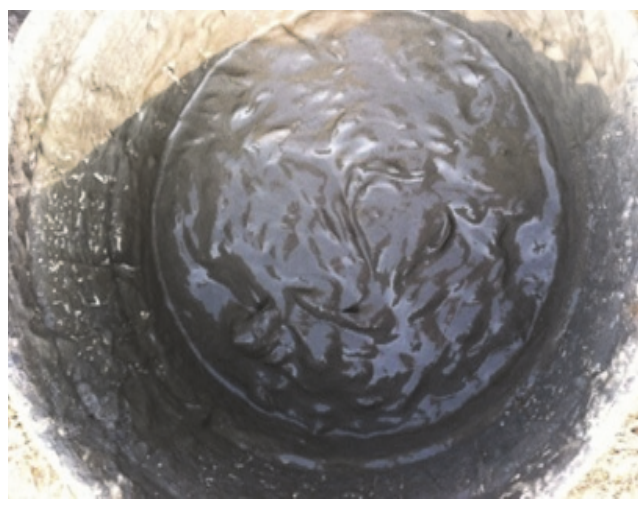

(f) Slurry mixing mucky soil

FIGURE 13: The mixing effect of the slurry blender with different additives.

both. Meanwhile, the fibre length signified no effect on the internal friction angle. Therefore, the length of the basalt fibre has a very important effect on the shearing performance of the cement-soil, and the optimal length is $12 \mathrm{~mm}$.

\section{Conclusions}

Based on the triaxial shear tests, improvements in the cementsoil reinforced by basalt fibre are studied, and the following conclusions were drawn.
(1) Basalt fibre is an effective reinforcement material for cement-soil, which can effectively enhance its shear strength.

(2) The optimal ratios of basalt fibre mixed in the cementsoil obtained through different triaxial tests are consistent; the optimal fibre length is $12 \mathrm{~mm}$, and the optimal mass ratio is $0.4 \%$.

(3) Mixing basalt fibre in the cement-soil can effectively increase its cohesive force and internal friction angle. 


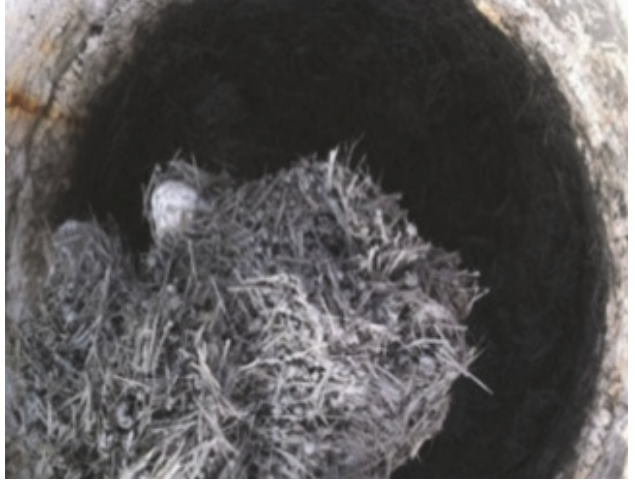

(a) Step 1

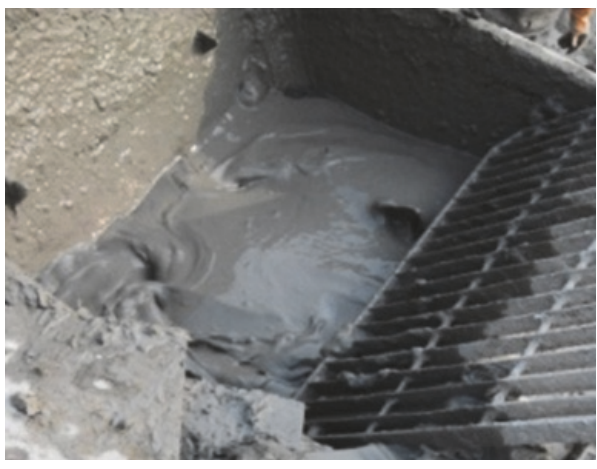

(c) Step 3

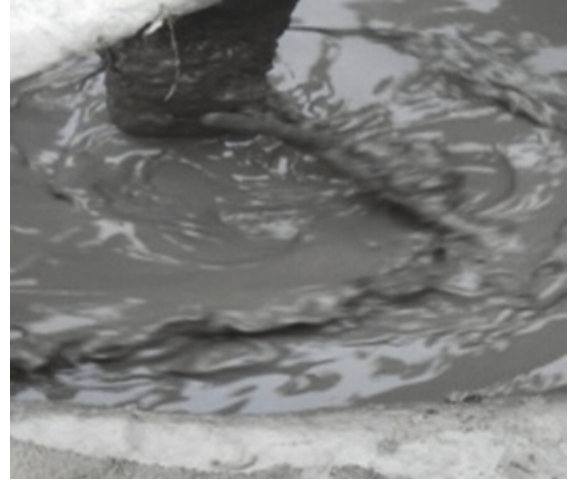

(b) Step 2

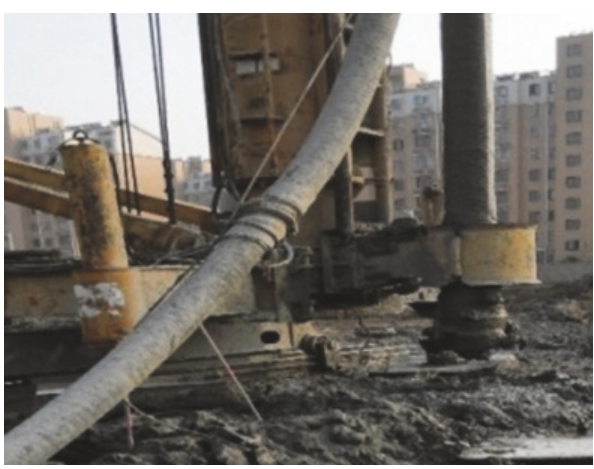

(d) Step 4

FIgURE 14: Site construction of cement-soil pile with basalt fibre.

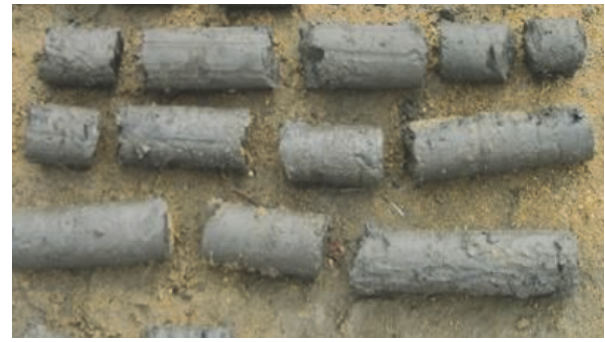

FIGURE 15: Core sample of cement-soil on site.

The cohesive force increased by $6.0 \sim 33.1 \%$, and the internal friction angle increased by $8.8 \sim 16.2 \%$.

(4) Using the proposed mix technology, the strength of the pile material collected at the site reached more than $70 \%$ of the artificial mixing cement-soil reinforced strength by the basalt fibre in the laboratory test.

In conclusion, the improvements in the tensile properties of the cement-soil, which is reinforced by basalt fibre, can effectively improve the overall mechanical performance. In practice, basalt fibre used in cement-soil mixing piles can enhance its horizontal bearing capacity to satisfy the needs of specific projects.

\section{Conflicts of Interest}

The authors declare that there are no conflicts of interest regarding the publication of this paper.

\section{References}

[1] W. Shubo, Experimental Research on the Additive of CementStabilized Soil in Laboratory, Tianjin University, Tianjin, China, 2007 (Chinese).

[2] D. O. A. Osula, "A comparative evaluation of cement and lime modification of laterite," Engineering Geology, vol. 42, no. 1, pp. 71-81, 1996.

[3] P. Wentai, Blenging Fly Ash Compound Cement Soil Mechanical Properties and Durability Research, Inner Mongolia Agricultural University, Neimenggu Zizhiqu, China, 2013 (Chinese).

[4] W. Wang, Study on Reinforcement Mechanism and Damage Performance of Cemented Soil Stabilized with Nanometer Material, Zhengjiang University, Zhenjiang, China, 2004 (Chinese).

[5] G. Kevin, N. M. Louay, and Z. Wu, "Laboratory mechanistic evaluation of soil cement mixtures with fibrillated-polypropylene-fibers," in Proceedings of the 82th Transportation Research Board Annual Meeting (TRB '03), Washington, DC, USA, January 2003.

[6] N. C. Consoli, P. D. M. Prietto, and L. A. Ulbrich, "Influence of fiber and cement addition on behavior of sandy soil," Journal of Geotechnical and Geoenvironmental Engineering, vol. 124, no. 12, pp. 1211-1214, 1998. 
[7] X. Tong, Test Study on Cement Soil Additive and its Damage Model, Zhengjiang University, Zhenjiang, China, 1998 (Chinese).

[8] Y. Huang, Z.-Z. Zhou, J. Bai, and Q.-F. Chen, "Micro-experiments on a soft ground improved by cement-mixed soils with gypsum additive," Chinese Journal of Geotechnical Engineering, vol. 32, no. 8, pp. 1179-1183, 2010 (Chinese).

[9] X. Wu, "Analysis on influence factors of compressive strength of cement-soil mixing piles," West-China Exploration Engineering, vol. 18, no. 2, pp. 28-30, 2006 (Chinese).

[10] X.-Q. Hu, "The overview of the present development of Basalt Fiber in China," Hi-Tech Fiber \& Application, vol. 33, no. 6, pp. 12-19, 2008 (Chinese).

[11] J. Sim, C. Park, and D. Y. Moon, "Characteristics of basalt fiber as a strengthening material for concrete structures," Composites Part B: Engineering, vol. 36, no. 6-7, pp. 504-512, 2005.

[12] M. Lund, Tensile Strength of Glass Fibres, Aalborg University, Aalborg, Denmark, 2010.

[13] J. M. Park and R. V. Subramanian, "Interfacial shear strength and durability improvement by monomeric and polymeric silanes in basalt fiber/epoxy single-filament composite specimens," Journal of Adhesion Science and Technology, vol. 5, no. 6, pp. 459-477, 1991.

[14] S. R. Kaniraj and V. Gayathri, "Behavior of fiber-reinforced cement-stabilized fly ashes," Journal of Testing and Evaluation, vol. 34, no. 4, pp. 290-297, 2006.

[15] N. C. Consoli and Zortéa, "FrancoStudies. On the dosage of fiber-reinforced cemented soils," Journal of Materials in Civil Engineering, vol. 23, no. 12, pp. 1624-1632, 2011. 

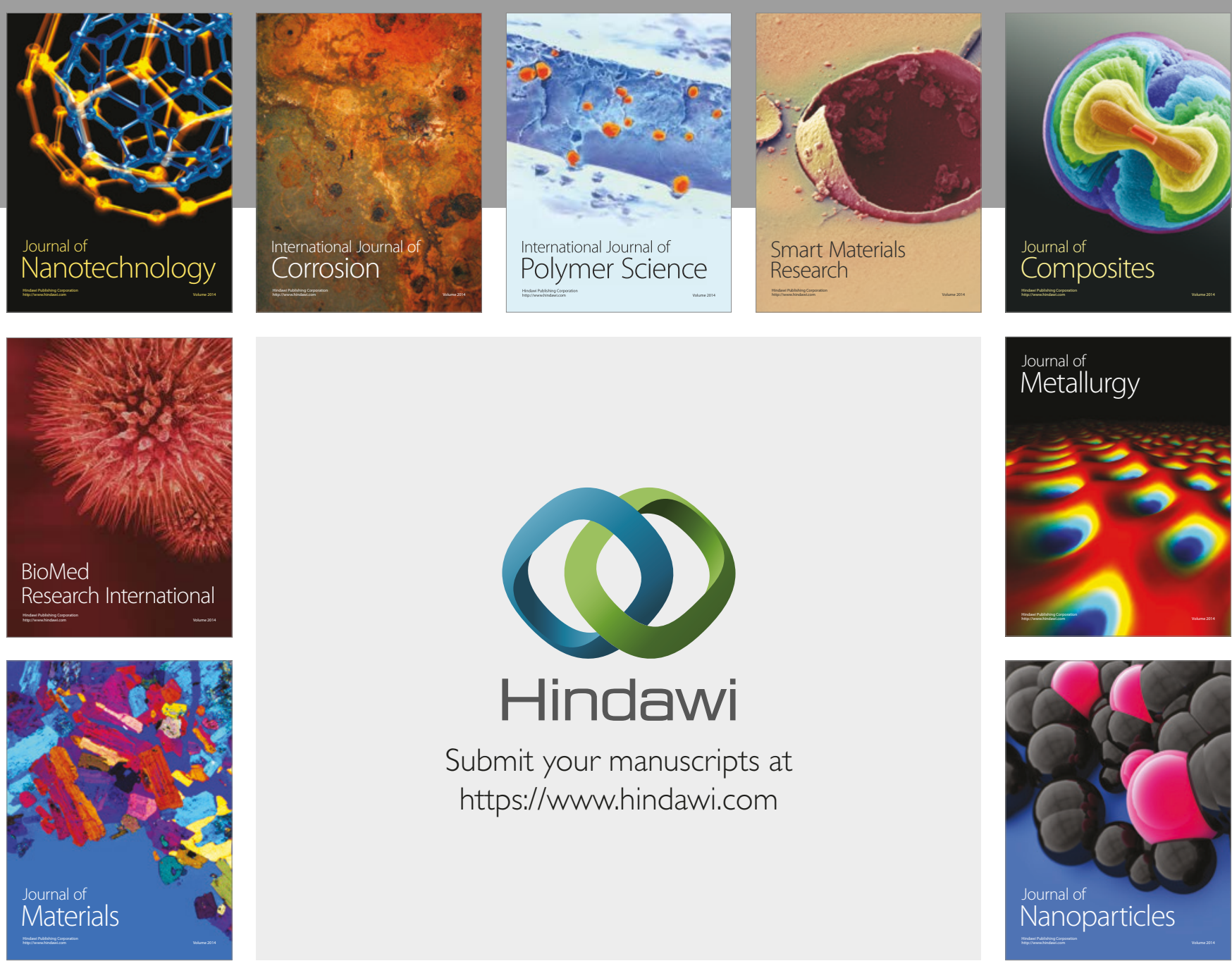

\section{Hindawi}

Submit your manuscripts at

https://www.hindawi.com
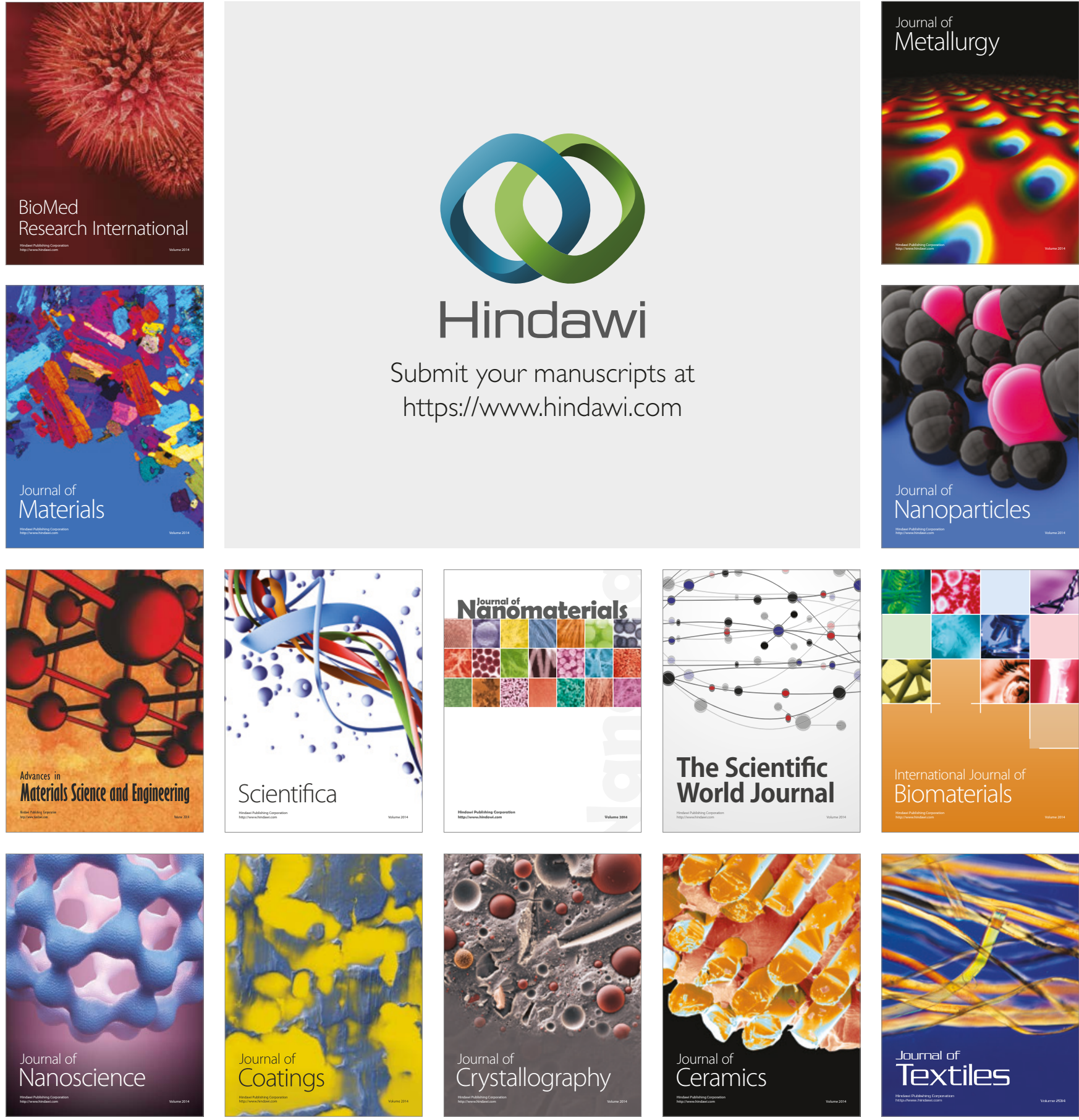

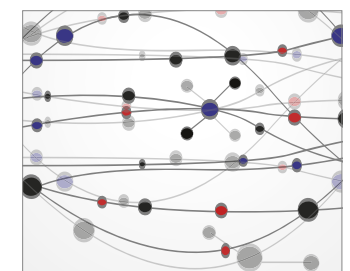

The Scientific World Journal
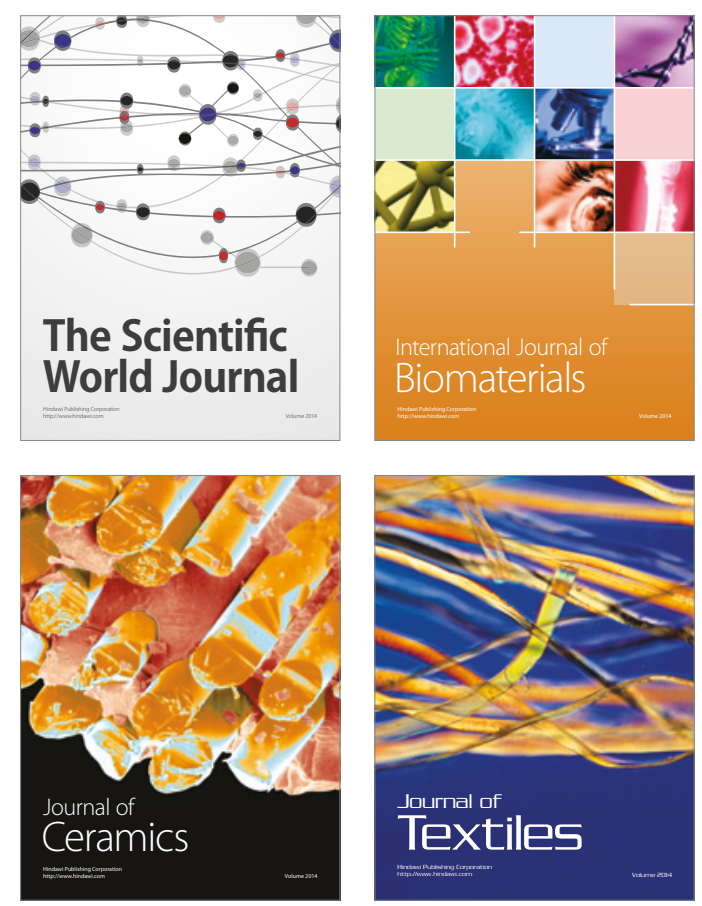